\title{
Three-dimensional cubic ordered mesoporous carbon (CMK-8) as highly efficient stable Pd electro-catalyst support for formic acid oxidation
}

\author{
T. Maiyalagan ${ }^{\mathrm{a}, \mathrm{b}, *}$, Abu Bakr A. Nassr ${ }^{\mathrm{c}, 1}$, T.O. Alaje ${ }^{\mathrm{a}}$, M. Bron ${ }^{\mathrm{c}}$, K. Scott ${ }^{\mathrm{a}}$ \\ ${ }^{a}$ School of Chemical Engineering and Advanced Materials, University of Newcastle upon Tyne, Newcastle upon Tyne NE1 7RU, United Kingdom \\ ${ }^{\mathrm{b}}$ School of Chemical and Biomedical Engineering, Nanyang Technological University, 50 Nanyang Drive, 639798 Singapore, Singapore \\ ${ }^{\mathrm{c}}$ Technische Chemie I, Institut für Chemie, Naturwissenschaftliche Fakultät II, Martin-Luther-Universität Halle-Wittenberg, von-Danckelmann-Platz 4, 06120 Halle, Germany
}

\section{A R T I C L E I N F O}

Article history:

Received 4 February 2012

Received in revised form

31 March 2012

Accepted 2 April 2012

Available online 10 April 2012

\section{Keywords:}

Pd nanoparticles

Electro-catalysts

Highly ordered mesoporous carbon

Formic acid

Electro-oxidation

Fuel cell

\begin{abstract}
A B S T R A C T
In this work, Pd nanoparticles were supported on two types of three-dimensional cubic highly ordered mesoporous carbon (CMK-8) by the sodium borohydride reduction method and the activity of the Pd/ CMK-8 electro-catalysts towards formic acid oxidation was evaluated and compared with that of commercial Pd/C (E-TEK) catalyst. The catalysts were characterized by transmission electron microscopy (TEM), X-ray diffraction (XRD), cyclic voltammetry, and chronoamperometry. Cyclic voltammetry revealed $\mathrm{Pd} / \mathrm{CMK}-8$ with larger pores as being the most electroactive with a mass specific activity $\left(\mathrm{mA} \mathrm{mg}_{\mathrm{Pd}}^{-1}\right.$ ) of 486.4 that exceeded not only that of the Pd/C (E-TEK) (386.5 mA mg-1) but also that of

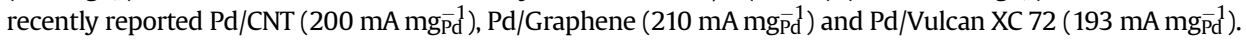
As demonstrated with chronoamperometry, the larger pore Pd/CMK-8 also proved to be the most stable catalyst. This exceptional performance can be ascribed to the very high surface area and la3d symmetry that yields a relatively isotropic graphitized structure with a high conductivity. In addition, the open framework of the 3-D bicontinous channels and highly ordered mesopores allows for an advanced mass transfer characteristics. The results show that CMK-8 support would significantly improve the power output and stability of Pd-based electro-catalysts for formic acid oxidation.
\end{abstract}

(c) 2012 Elsevier B.V. All rights reserved.

\section{Introduction}

Recently there has been increased interest in the development of direct formic acid fuel cells (DFAFCs) [1-8]. The advantages of direct formic acid fuel cells as power sources are the lower fuel crossover through the polymer membranes, the lower toxicity of formic acid as a fuel (however, it should be noted that formic acid is corrosive) and the fast oxidation kinetics of formic acid in comparison with methanol which make their application in portable devices more advantageous than direct methanol fuel cells $[9,10]$.

It is well known that Pt is a good catalyst for formic acid electrooxidation, with the oxidation following the dual path mechanism represented by the following Eqs. (1) and (2):

$\mathrm{HCOOH} \rightarrow \mathrm{CO}_{2}+2 \mathrm{H}^{+}+2 \mathrm{e}^{-}$(deprotonation step)

\footnotetext{
* Corresponding author. Tel.: +65 63168790.

E-mail address: maiyalagan@gmail.com (T. Maiyalagan).

1 On leave from, Electronic Materials Research Department, Institute of Advanced Technology and New Materials, City for Scientific Research and Technological Applications, Alexandria, Egypt.
}

$\mathrm{HCOOH} \rightarrow \mathrm{CO}_{\mathrm{ads}}+\mathrm{H}_{2} \mathrm{O} \rightarrow \mathrm{CO}_{2}+2 \mathrm{H}^{+}+2 \mathrm{e}^{-}$(dehydration step) (2)

According to the above equations, the oxidation of formic acid on Pt follows two pathways. The first is the direct mechanism in which formic acid is oxidized completely into $\mathrm{CO}_{2}$ through deprotonation (Eq. (1)). In the second, formic acid is oxidized through dehydration by the formation of a reactive intermediate (CO) which is further oxidized into $\mathrm{CO}_{2}$; the later mechanism is called the indirect mechanism (Eq. (2)) [11]. The direct mechanism is beneficial because no intermediates are formed during the oxidation process thus preventing poisoning of the catalyst surface with $\mathrm{CO}$ molecules which is the main problem with Pt electro-catalyst. Catalyst poisoning blocks the platinum active sites available for further formic acid oxidation and reduces the efficiency of the oxidation process during long-term operations. While bi- and multimetallic Pt catalysts have been successfully implemented to lower CO poisoning [12], the high price of platinum is also a setback to its use for commercial applications.

In an effort to reduce the cost of catalysts used for formic acid oxidation, attention has shifted to non-Pt materials such as Pd [13]. Results obtained show that Pd is a good electro-catalyst for formic 
acid oxidation on which the mechanism of oxidation follows the deprotonation pathway thus preventing catalysts poisoning [11].

In addition to the development of efficient electro-catalysts, another approach to improve fuel cell performance is to develop alternative catalysts supports. Carbon black (e.g. Vulcan XC 72) is the commonly used support material. However, it is essentially nonporous with a low surface area, leading to low utilization of $\mathrm{Pt}$ catalysts. The most important factors affecting the choice of support are its chemical nature as well as the presence of surface functional groups. These functional groups can determine the dispersion and stability of the metal nanoparticles as well as the electronic properties of the metal. They also influence metal support interactions, the degree of alloying in multimetallic catalyst, mass transfer resistance, and the ohmic resistance of the catalyst layer. Carbon nanofibers (CNF) [14-16], carbon nanotubes (CNT) [17-19], nitrogen doped carbon nanotubes (N-CNT) [20-22] and ordered mesoporous carbon (OMC) [23-25] provide alternative promising candidates as carbon support [26] for fuel cell applications. Ordered mesoporous carbon (OMC) would be an ideal electro-catalyst support in fuel cell electrodes due to its high surface area, high conductivity and enhanced mass transport within the pore channels [27,28].

In this study, three-dimensional cubic ordered mesoporous carbon (CMK-8) with two different pore diameters was used as support to prepare Pd-based electro-catalysts (Pd/CMK-8) for formic acid electro-oxidation. The performance of the prepared catalysts was compared with commercial Pd supported on carbon black (Pd/C).

\section{Experimental}

\subsection{Synthesis of three-dimensional cubic ordered mesoporous carbon (CMK-8)}

Mesoporous silica was synthesized as follows [29]. Typically, $6 \mathrm{~g}$ Pluronic P123 (poly(ethylene oxide)-poly(propylene oxide)poly(ethylene oxide), PEO20-PPO70-PEO20) was dissolved in $217 \mathrm{~g}$ of deionized water and $11.628 \mathrm{~g}$ of $37 \mathrm{wt} \%$ conc. $\mathrm{HCl}$ solution with stirring at $35^{\circ} \mathrm{C}$. After complete dissolution, $6 \mathrm{~g}$ of butanol was added at once with vigorous stirring. After $1 \mathrm{~h}$ of stirring, $12.9 \mathrm{~g}$ of tetraethyl-orthosilicate (TEOS) was added at once to the homogenous clear solution while still stirring. The mixture was left under vigorous and constant stirring for $24 \mathrm{~h}$ at $35^{\circ} \mathrm{C}$. Afterwards, the mixture was placed in an oven at $100{ }^{\circ} \mathrm{C}$ and left for $24 \mathrm{~h}$ under static conditions in a closed polypropylene bottle. The solid product obtained after hydrothermal treatment was filtered while hot and then dried at $100{ }^{\circ} \mathrm{C}$ without washing. To complete the synthesis, the template was removed by extraction in an ethanol- $\mathrm{HCl}$ mixture; this was done by stirring the filtrate for $1-2 \mathrm{~h}$ in a mixture of $300-400 \mathrm{ml}$ ethanol with $20-30 \mathrm{ml} 37 \%$ conc. $\mathrm{HCl}$ followed by calcination in air at $550{ }^{\circ} \mathrm{C}$ for $6 \mathrm{~h}$. Two different silica templates labeled KIT-6-I and II were obtained by varying the mole ratio of reactants in the following order: TEOS:P123: $\mathrm{HCl}: \mathrm{H}_{2} \mathrm{O}: \mathrm{BuOH}(1: 0.0167: 1.83: 194.7: 1.31)$ and (2:0.0259:1.83:194.7:2.03), respectively.

The mesoporous carbon was prepared using a slight modification of a reported procedure [30]. Typically $1.25 \mathrm{~g}$ of sucrose and $0.14 \mathrm{~g} \mathrm{H}_{2} \mathrm{SO}_{4}$ were added to $5 \mathrm{~g}$ of deionized water. This was mixed with $1 \mathrm{~g}$ of KIT- 6 mesoporous silica. The mixture was dried in an oven at a temperature of $100{ }^{\circ} \mathrm{C}$ for $6 \mathrm{~h}$; the temperature was increased to $160^{\circ} \mathrm{C}$ and maintained for another $6 \mathrm{~h}$. To the partially decomposed sucrose was added a sucrose solution prepared with $0.75 \mathrm{~g}$ sucrose and $0.08 \mathrm{~g} \mathrm{H}_{2} \mathrm{SO}_{4}$ in $5 \mathrm{~g}$ of water and the drying procedure was repeated. The carbon-silica composite was pyrolyzed in flowing nitrogen at a temperature of $900{ }^{\circ} \mathrm{C}\left(\mathrm{N}_{2}\right.$ flow: $50 \mathrm{ml} \mathrm{min}^{-1}$; heating rate $2{ }^{\circ} \mathrm{Cmin}^{-1}$ ) for $4 \mathrm{~h}$. The carbon was recovered by dissolving the silica template in $1 \mathrm{M}$ ethanolic sodium hydroxide ( $50 \%$ water $-50 \%$ ethanol v/v), filtering and washing with ethanol. Finally, the resultant carbon was dried at $100^{\circ} \mathrm{C}$ for $12 \mathrm{~h}$. CMK-I and II were obtained by using KIT-6-I and II as hard templates, respectively.

\subsection{Synthesis of the electro-catalysts}

In this work carbon supported Pd nanoparticles electro-catalyst with $20 \%$ wt of metal loading on carbon were prepared using a wet chemical reduction method. Typically, the mesoporous carbon (40 mg) was ultrasonically dispersed in a mixture of ultra-pure water and isopropyl alcohol (with a volume ratio of $1: 1$ ) for 20 min after which the desired amount of $0.01 \mathrm{M} \mathrm{PdCl}_{2}$ in deionized water was added. The mixture was stirred for $30 \mathrm{~min}$. The $\mathrm{pH}$ of the ink was adjusted to $\mathrm{pH}=9$ by adding a drop $\mathrm{NaOH}$ solution and then its temperature was increased to $80^{\circ} \mathrm{C}$. $25 \mathrm{ml}$ of $0.2 \mathrm{~mol} \mathrm{~L}^{-1}$ solution of sodium borohydride was added into the ink drop by drop, and the bath was stirred for $1 \mathrm{~h}$. The mixture was cooled, dried and washed repeatedly with ultra-pure water $\left(18.2 \mathrm{M} \Omega \mathrm{cm}^{-1}\right)$ to remove excess chlorides. The catalyst powder was dried in an oven. All chemicals used were of analytical grade. The catalysts prepared with CMK-I and CMK-II were denoted as Pd/ CMK-8-I and Pd/CMK-8-II, respectively.

\subsection{Catalyst characterization}

Powder X-ray diffraction was recorded on a PAN analytical X'Pert Pro MPD diffractometer using $\mathrm{CuK}_{\alpha}$ radiation. For transmission electron microscopic studies, catalysts dispersed in ethanol were placed on a copper grid and transmission electron micrographs (TEM) were taken using a Tecnai G2 F20 X-Twin (FEI company, Eindhoven, the Netherlands), operating at an accelerating voltage of $200 \mathrm{keV}$. Nitrogen porosimetry using a Micromeritics ASAP 2000 was used to determine pore size distribution and surface area of mesoporous carbon. Metal loading was determined by thermogravimetric analysis (TGA) carried out on a Perkin Elmer TGA7 with a heating rate of $10^{\circ} \mathrm{C} \mathrm{min}^{-1}$ in air with a flow rate of $40 \mathrm{ml} \mathrm{min}^{-1}$ up to a temperature of $800{ }^{\circ} \mathrm{C}$. Under these conditions the carbon is completely oxidized, allowing for the determination of Pd loading.

\subsection{Electrochemical measurement}

All electrochemical measurements were performed using an Autolab PGSTAT128N potentiostat/galvanostat. A three compartment electrochemical cell has been used in which the catalyst coated glassy carbon $\left(0.155 \mathrm{~cm}^{2}\right)$, Pt foil and $\mathrm{Ag} / \mathrm{AgCl}$ (saturated $\mathrm{KCl}$ solution) were used as working, counter and reference electrodes, respectively. All the electrochemical experiments were carried out at room temperature in $0.5 \mathrm{M} \mathrm{H}_{2} \mathrm{SO}_{4}$ and $0.5 \mathrm{M} \mathrm{HCOOH} / 0.5 \mathrm{M}$ $\mathrm{H}_{2} \mathrm{SO}_{4}$. The electrolyte solution was purged with high purity nitrogen for 30 min prior to a series of voltammetric experiments. The base voltamogram for all electrodes was recorded after reproducible voltammograms in $0.5 \mathrm{M} \mathrm{H}_{2} \mathrm{SO}_{4}$ were obtained and the cycle number 50 in $0.5 \mathrm{M} \mathrm{HCOOH} / 0.5 \mathrm{M} \mathrm{H}_{2} \mathrm{SO}_{4}$ was used for electro-catalytic activity evaluation. To test the stability and durability of electro-catalysts, chronoamperometric measurements (current-time curves) were recorded at $0.3 \mathrm{~V}$ for $3600 \mathrm{~s}$ in $0.5 \mathrm{M}$ $\mathrm{HCOOH} / 0.5 \mathrm{M} \mathrm{H}_{2} \mathrm{SO}_{4}$.

\subsection{Preparation of the working electrode}

A glassy carbon electrode $\left(0.155 \mathrm{~cm}^{2}\right)$ was polished to a mirror finish with $1 \mu \mathrm{m}$ and $0.3 \mu \mathrm{m}$ alumina suspension successively. The 
polished electrode was washed with ethanol/water solution $(1: 1, \mathrm{~V} /$ $\mathrm{V})$ and then ultrasonicated in ultra-pure water each for $10 \mathrm{~min}$. After that, the electrode is ready to serve as an underlying substrate of the working electrode. The electrodes for the electrochemical measurements were fabricated by dispersing $2.5 \mathrm{mg}$ of $\mathrm{Pd} / \mathrm{CMK}-8$ in $150 \mu \mathrm{L}$ isopropanol and $50 \mu \mathrm{L}$ of Nafion solution (5\% wt.) and then sonicating for $1 \mathrm{~h}$ and stirring for at least $3 \mathrm{~h}$. Five microliters of the suspension were dropped on to the glassy carbon electrode and the solvent was evaporated at room temperature.

\section{Results and discussions}

\subsection{Physicochemical characterization}

Fig. 1 shows the TEM images of the KIT-6 template (1a) and CMK-8 ordered mesoporous carbon (1b). The highly regular pore structure of both the template and the mesoporous carbon is clearly visible in these figures. The structural properties of the synthesized ordered mesoporous carbon (CMK-8) were obtained with $\mathrm{N}_{2}$ porosimetry. The mesoporous carbon (CMK-8) exhibits remarkably higher surface area than Vulcan XC 72R $\left(235 \mathrm{~m}^{2} \mathrm{~g}^{-1}\right)$ [31]. The BET specific surface areas of the mesoporous carbons are 1060 and $1149 \mathrm{~m}^{2} \mathrm{~g}^{-1}$ for CMK-8-I and CMK-8-II, respectively, while the respective pore diameters are 4.9 and $3.2 \mathrm{~nm}$. [32]. Threedimensional ordered mesoporous carbons (CMK-8) thus obtained are characterized by high surface area $\left(>1000 \mathrm{~m}^{2} \mathrm{~g}^{-1}\right)$, large pore volumes, and a highly regular interconnected pore structure that could allow for a good dispersion of catalyst nanoparticles. Thus, they have been used as catalyst support for Pd nanoparticle electro-
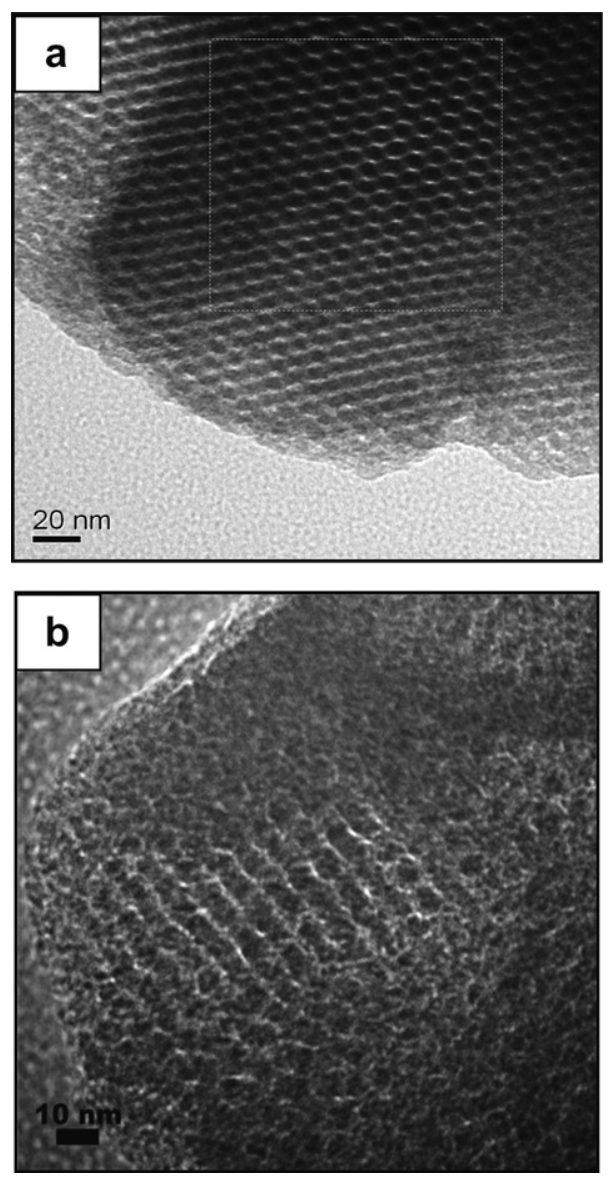

Fig. 1. TEM images of (a) KIT-6-I and (b) CMK-8-I ordered mesoporous carbon.
Table 1

Comparison of activity for formic acid oxidation on various electro-catalysts.

\begin{tabular}{|c|c|c|c|c|c|c|}
\hline \multirow[t]{2}{*}{ S.No } & \multirow[t]{2}{*}{ Electro-catalysts } & \multicolumn{2}{|c|}{ Particle size $(\mathrm{nm})$} & \multirow{2}{*}{$\begin{array}{l}\text { Pd wt.\% } \\
\text { by TGA } \\
\text { method }\end{array}$} & \multirow{2}{*}{$\begin{array}{l}\text { EASA } \\
\left(\mathrm{cm}^{2} \mathrm{mg}_{\mathrm{Pd}}^{-1}\right)\end{array}$} & \multirow{2}{*}{$\begin{array}{l}\text { Mass } \\
\text { specific } \\
\text { activity } \\
\left(\mathrm{mA} \mathrm{mg}{ }^{-1} \mathrm{Pd}\right)\end{array}$} \\
\hline & & XRD & TEM & & & \\
\hline 1 & Pd/Vulcan XC-72 & - & - & - & - & $193^{\mathrm{a}}$ \\
\hline 2 & $\mathrm{Pd} / \mathrm{CNT}$ & 5.4 & 6.2 & - & - & $200^{\mathrm{b}}$ \\
\hline 3 & Pd/Graphene & - & 10 & - & - & $210^{\mathrm{a}}$ \\
\hline 4 & $\mathrm{Pd} / \mathrm{C}(\mathrm{E}-\mathrm{TEK})$ & 3.7 & 4.7 & 22 & 210 & 386.5 \\
\hline 5 & Pd/CMK-8-I & 4.5 & 3.6 & 20.48 & 287 & 486.4 \\
\hline 6 & Pd/CMK-8-II & 4.7 & 4.1 & 20.26 & 256 & 470.3 \\
\hline
\end{tabular}

catalysts prepared as detailed in Section 2. The amount of Pd present in each type of catalysts was determined by TGA and the values are tabulated in Table 1 . The average weight percentage of Pd obtained from measurements was found to be $\sim 20 \%$ for all the catalysts prepared in this work.

The X-ray powder diffraction patterns of all catalysts used in this study (Pd/CMK-8-I, II and Pd/C) are shown in Fig. 2. Note that the broad peak centered at ca. $25^{\circ}$ corresponds to the carbon used as the supporting matrix; therefore, it is invariably observed in all the patterns. For all the samples, all peaks expected for an fcc lattice, corresponding to the structure of the pure bulk Pd metal are observed. The average crystallite size of the Pd can be calculated using the Debye-Scherrer formula $[33,34]$ :

$d=0.89 \lambda / B_{2 \theta} \cos \theta$

where $d$ is the crystallite size, $\lambda$ is the wavelength, $B_{2 \theta}$ is the full width at half maximum of the peak and $\theta$ is the diffraction angle.

The crystallite size was calculated from the peak corresponding to Pd (220) crystal face in order to avoid the influence of the carbon support. Table 1 summarizes the average crystallite sizes of the catalysts estimated by the Scherrer formula [33,34]. The average size of Pd crystallites decreases slightly from 4.7 to $4.5 \mathrm{~nm}$ when the pore size increases, while $\mathrm{Pd} / \mathrm{C}$ possesses the smallest $\mathrm{Pd}$ crystallites.

Fig. 3 shows the TEM images of the Pd catalysts used in this study. It can be seen that for all supported Pd catalysts, the particles are uniformly dispersed and studded on the surface of the carbon, with $\mathrm{Pd} / \mathrm{C}$ showing additionally highly agglomerated particles. As

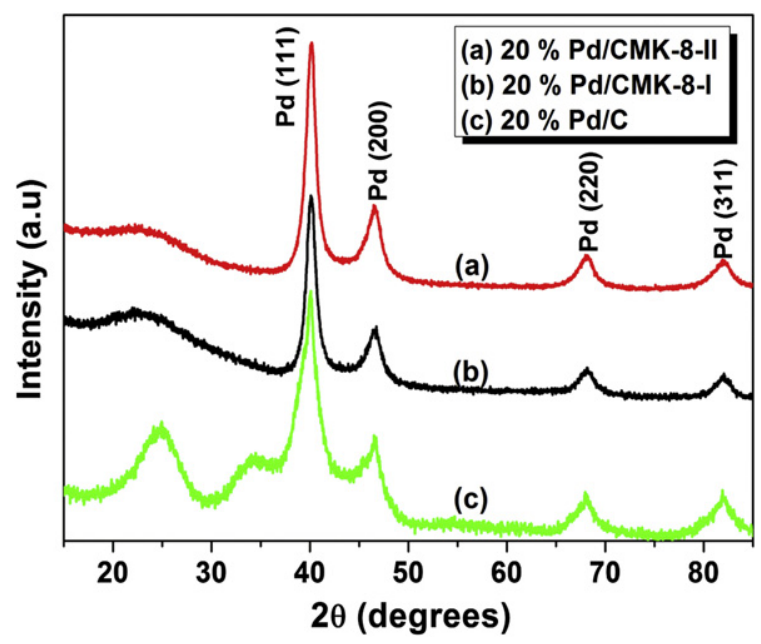

Fig. 2. XRD patterns of (a) 20\% Pd/CMK-8-II; (b) $20 \%$ Pd/CMK-8-I; and (c) $20 \% \mathrm{Pd} / \mathrm{C}$ electro-catalysts. 
can be seen from Fig. 3b, there are metal particles dispersed on the outside of ordered mesoporous carbon. Though the ordered mesochannels are somewhat unapparent in the TEM images of Pd/ CMK-8, they exhibit that the particles are dispersed within the
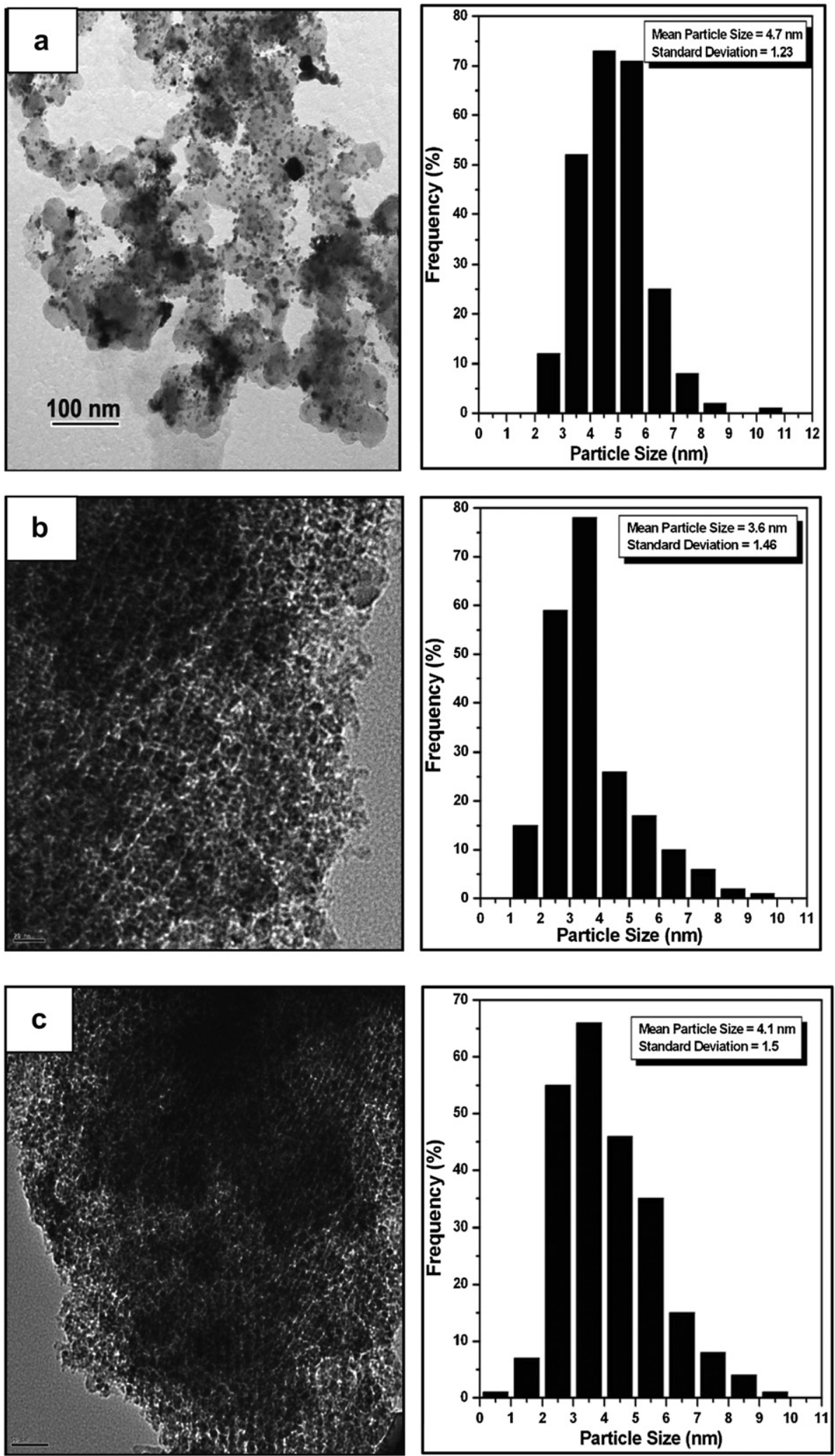

Fig. 3. TEM images and the corresponding histogram for particle size distribution of (a) Pd/C; (b) Pd /CMK-8-I; and (c) Pd/CMK-8-II catalysts. carbon support uniformly. The mean particle sizes of about 4.1 and $3.6 \mathrm{~nm}$ are in fairly good agreement with the crystallite sizes obtained with XRD (see Table 1). However, larger particles are also present (see Fig. 3) which may indicate that parts of the 
nanoparticles are deposited on the outer surface of the support. Notably, TEM images clearly reveal that even after the metal loading, the highly ordered structure of mesoporous carbon (CMK8) was maintained which is important for fast diffusion of formic acid to the catalytic sites.

Due to their advantageous properties, as demonstrated above, the three-dimensional ordered mesoporous carbons (CMK-8) are promising supports for stabilizing Pd nanoparticle electrocatalysts. The highly ordered mesoporous structure could allow for an efficient mass transport (reactants/products and electrolytes). The materials were thus tested as electro-catalyst for formic acid oxidation.

\subsection{Electrochemical characterization}

The electrochemically active surface area (ECSA) can provide important information on the available active sites of catalysts. Cyclic voltammograms of the Pd/CMK-8 and Pd/C electro-catalysts in $0.5 \mathrm{M} \mathrm{H}_{2} \mathrm{SO}_{4}$ solution carried out in the range of -0.2 to $1.0 \mathrm{~V}$ $(\mathrm{Ag} / \mathrm{AgCl})$ with a sweep rate of $100 \mathrm{mV} \mathrm{s}^{-1}$ are shown in Fig. 4. It is clear from the figure that all electro-catalysts showed the expected behavior of a Pd electrode in sulfuric acid solution with characteristic and well defined hydrogen adsorption/desorption peaks around $0 \mathrm{~V}$ and $\mathrm{adO} \mathrm{Pd}_{x}$ reduction peak in the reverse scan at ca. $0.5 \mathrm{~V}$. Also, the formation of $\mathrm{PdO}_{x}$ at higher potential in the forward scan can be detected. All these features are typical for Pd catalysts in sulfuric acid solution and agree well with the reported data [35-38]. The only difference between the CVs is that the Pd supported on CMK-8 showed higher double layer capacitance and this may be attributed to higher surface area of CMK-8 in comparison with carbon Vulcan XC 72R used as a support for the commercial catalyst. Since the hydrogen adsorption/desorption on Pd may be overlapped by hydrogen absorption/dissolution in Pd [39], we calculate the electrochemical surface area using the charge consumed during the $\mathrm{PdO}_{x}$ reduction in the course of the cathodic scan and using the value of $0.424 \mathrm{mC} \mathrm{cm}^{-2}$ as charge consumed for monolayer oxide reduction, a procedure which is well established in literature $[40,41]$. The electrochemical surface areas are listed in Table 1; the ECSA of Pd/ CMK-8-I, Pd/CMK-8-II and Pd/C (E-TEK) catalysts were $287 \mathrm{~cm}^{2} \mathrm{mg}_{\mathrm{Pd}}^{-1}, 256 \mathrm{~cm}^{2} \mathrm{mg}_{\mathrm{Pd}}^{-1}$ and $210 \mathrm{~cm}^{2} \mathrm{mg}_{\mathrm{Pd}}{ }^{-1}$ Both Pd/CMK-8 catalysts have a higher electrochemical specific surface area than the commercial Pd/C catalysts, and the increase in surface area agrees well with the decrease in particle size determined by TEM. On the other hand, it does not fit to the order of crystallite sizes determined by XRD, which, however, is attributed to the fact that crystallite sizes and not particle sizes are determined by XRD and agglomeration of individual particles or amorphous overlayers will not be detected. The higher electrochemically active surface area (ECSA) of Pd obtained with the three-dimensional ordered mesoporous carbon (CMK-8) support compared to that obtained with the Vulcan XC 72R support (Table 1) confirms the better dispersion of Pd, while $\mathrm{Pd} / \mathrm{C}$ shows some agglomeration (see Fig. 3a). The high dispersion of Pd nanoparticles is due to the higher surface area $\left(>1000 \mathrm{~m}^{2} \mathrm{~g}^{-1}\right.$ ) of the three-dimensional ordered mesoporous carbon (CMK-8) support compared to those of Vulcan XC $72 \mathrm{R}$ $\left(235 \mathrm{~m}^{2} \mathrm{~g}^{-1}\right)$ [31]. Highest utilization of Pd has been achieved with the three-dimensional ordered mesoporous carbon (CMK-8-I) support with the larger pore diameter. This suggests that the pore diameter of three-dimensional ordered mesoporous carbon (CMK8-I) has a decisive effect on the electrochemical surface area and Pd utilization. One reason might be a more facile nanoparticle formation inside these pores compared to CMK-8-II and thus less accumulation of larger particles on the outside (see also particle size distribution in Fig. 3) as well as a better stabilization of nanoparticles compared to Vulcan XC $72 \mathrm{R}$.

\subsection{Electro-catalytic activity of catalysts towards formic acid oxidation}

The electro-catalytic activity of all catalysts was evaluated by recording the CVs for all catalysts in $0.5 \mathrm{M} \mathrm{HCOOH} / 0.5 \mathrm{M} \mathrm{H}_{2} \mathrm{SO}_{4}$.
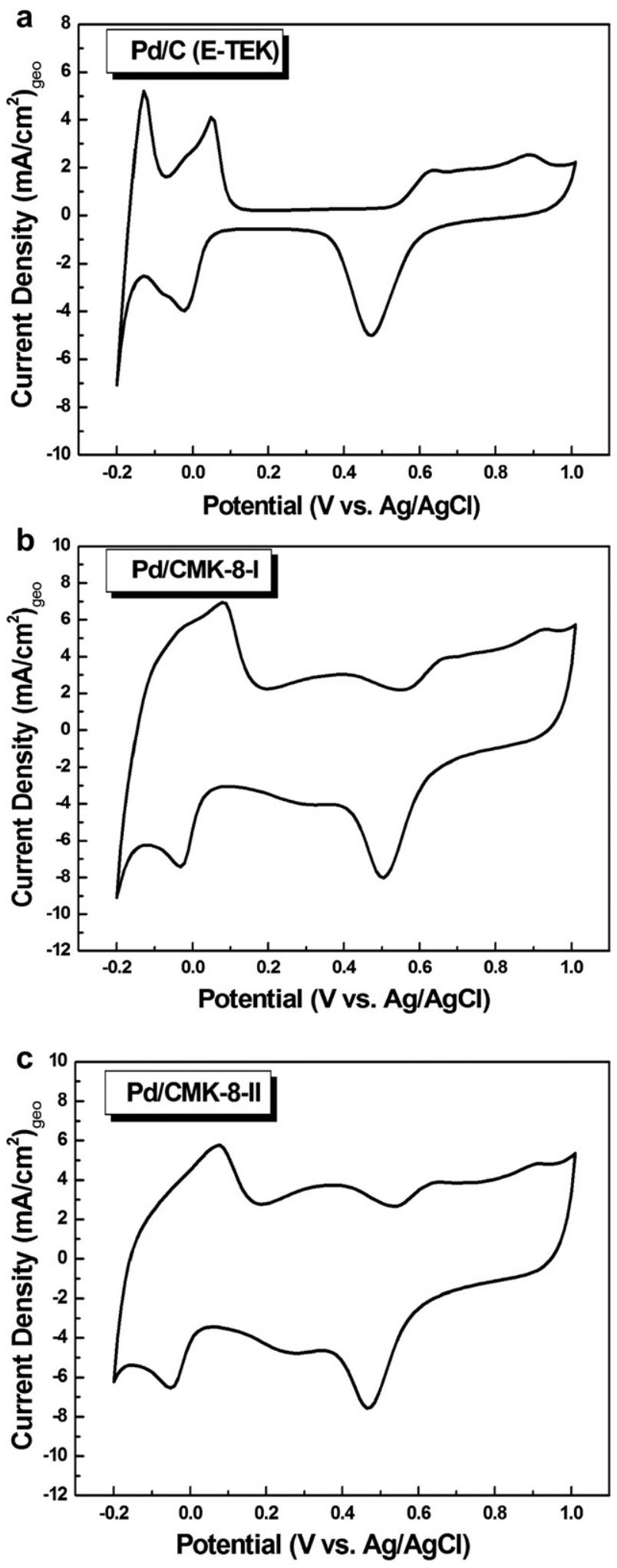

Fig. 4. Cyclic voltammograms of (a) Pd/C; (b) Pd/CMK-8-I; and (c) Pd/CMK-8-II electrocatalysts in $0.5 \mathrm{M} \mathrm{H}_{2} \mathrm{SO}_{4}$ solution at a scan rate of $100 \mathrm{mV} \mathrm{s}^{-1}, 25^{\circ} \mathrm{C}$. 
Fig. 5 shows the respective CVs. During the forward scan, all the catalysts showed a very small peak at about $-0.13 \mathrm{~V}$ due to hydrogen oxidation and the main peak for formic acid oxidation in the potential range between 0.35 and $0.45 \mathrm{~V}$. The later peak corresponds to the oxidation of formic acid through the direct mechanism (deprotonation pathway) [42]. On the other hand, only Pd supported on CMK-8-II with smaller pores showed a second broad peak at higher potential $(>0.6 \mathrm{~V})$ adjacent to the first peak at $0.35 \mathrm{~V}$, which in the other CVs is visible, if at all, only as very small shoulder. This peak could be attributed to the oxidation of adsorbed $\mathrm{CO}$ and formic acid on available active sites recovered by $\mathrm{CO}$ removal. The same behavior has been reported for formic acid oxidation on bulk Pd electrodes [43]. However, it is more likely that this peak can be attributed to adsorbed CO only since it is detected in the higher potential region $(>0.6 \mathrm{~V})$, i.e. the same region at which $\mathrm{PdO}_{x}$ is formed (Fig. 4, CV in $\mathrm{H}_{2} \mathrm{SO}_{4}$ ), which is inactive for formic acid oxidation. This result indicates that the formic acid oxidation on the surface of Pd supported on CMK-8-II with smaller pores likely proceeds via the dual pathway mechanism to a much larger extent than on the other catalysts. The theory behind this cannot be fully explained at the moment.

The as prepared Pd/CMK-8-I catalyst manifests a very high activity for formic acid electro-oxidation. It is clear from Fig. 5 that the oxidation current for formic acid in the forward scan is higher than that for reverse scan which reflects the higher activity and fast oxidation of adsorbed species on these catalysts. On the other hand, the commercial catalysts showed the opposite (a higher current $i_{\mathrm{b}}$ for the reverse scan). The electro-catalytic activity was evaluated based on the current density at the peak potential in the forward scan and normalized to the metal loading in the electrode. The results are tabulated in Table 1 . Among all the catalysts, the Pd supported on CMK-8-I with large pores showed the highest mass specific electro-catalytic activity for formic acid electro-oxidation reaction. The higher activity of $\mathrm{Pd} / \mathrm{CMK}-8$-I catalysts compared to $\mathrm{Pd} / \mathrm{C}$ catalyst could be due to high conductivity of the CMK- 8 support and highly distributed Pd nanoparticles. Pd/CMK-8-I catalysts have higher ECSA and higher activity compared to Pd/ CMK-8-II catalysts. It should be pointed out that Pd/CMK-8-I exhibits a very high mass activity of $486 \mathrm{~mA} \mathrm{mg}^{-1}$, which is nearly double that of recently reported palladium supported graphene $\left(210 \mathrm{~mA} \mathrm{mg}^{-1}\right), \mathrm{Pd} / \mathrm{CNT}\left(200 \mathrm{~mA} \mathrm{mg}^{-1}\right)$ and $\mathrm{Pd} / \mathrm{C}$ catalysts $\left(190 \mathrm{~mA} \mathrm{mg}^{-1}\right)[44,45]$.

\subsection{Stability test}

Chronoamperometric (CA) measurements are used to test the initial stability of the prepared catalysts. Fig. 6 shows the CA curves recorded at $0.3 \mathrm{~V}$ for $1 \mathrm{~h}$ in $0.5 \mathrm{M} \mathrm{HCOOH} / 0.5 \mathrm{M} \mathrm{H}_{2} \mathrm{SO}_{4}$. The current of a typically prepared Pd/CMK-8-I electrode for formic acid oxidation remains higher than the other catalysts, which indicates that the Pd/CMK-8-I has a better catalytic activity for formic acid oxidation and a higher stability during the tested time period. It can also be observed that during the first $15 \mathrm{~min}$, the commercial catalysts showed higher current density. However, during one hour of operation, the activity of the commercial catalyst decreased dramatically. On the other hand, the Pd catalysts supported on the CMK-8 showed better activity and stability over the entire length of time. A frequent spike in the CA curve for Pd/CMK-8-II with smaller pores is observed due to the removal of $\mathrm{CO}_{2}$ bubbles accumulated on the electrode surface. These were produced during the oxidation process of formic acid. From CA measurements we can conclude that Pd electro-catalysts supported on ordered mesoporous carbon have a higher electro-catalytic activity and stability than the commercial catalysts. This significant activity and stability is expected from the higher surface area of the support which
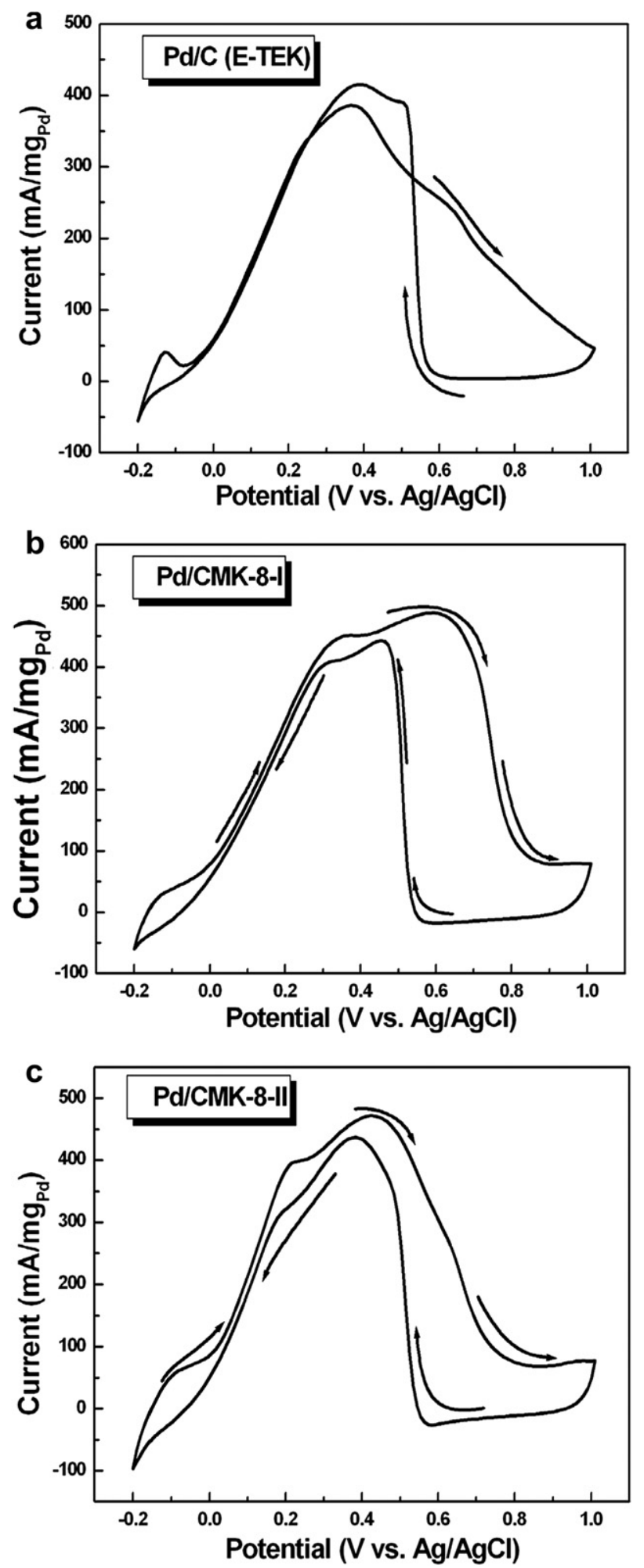

Fig. 5. Cyclic voltammograms of formic acid electro-oxidation on (a) $\mathrm{Pd} / \mathrm{C}$; (b) $\mathrm{Pd} /$ CMK-8-I; and (c) Pd/CMK-8-II electro-catalysts in $0.5 \mathrm{M} \mathrm{H}_{2} \mathrm{SO}_{4} / 0.5 \mathrm{M}$ HCOOH solution at a scan rate of $100 \mathrm{mV} \mathrm{s}^{-1}$ (recorded after 50 scans), $25^{\circ} \mathrm{C}$.

maintains high dispersion and small nanoparticle size of the prepared catalysts. The Pd/CMK-8-I sample was found to possess the best electro-catalytic performance and improved durability thus substantiating its potential as a promising anodic electrocatalyst in formic acid fuel cells. 


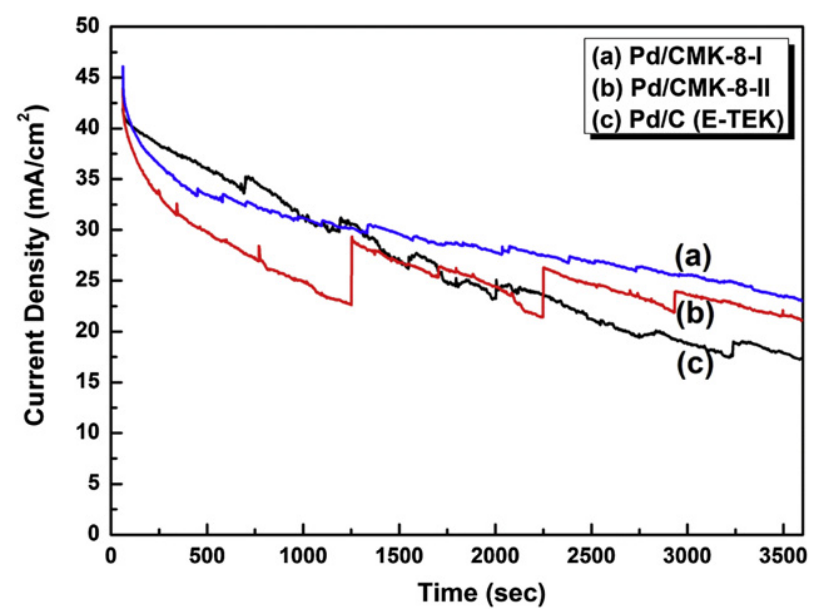

Fig. 6. Current density-time curves at $0.3 \mathrm{~V}$ for $3600 \mathrm{~s}$ at (a) Pd/CMK-8-I; (b) Pd/CMK8-II; and (c) Pd/C electro-catalysts in $0.5 \mathrm{M} \mathrm{H}_{2} \mathrm{SO}_{4} / 0.5 \mathrm{M} \mathrm{HCOOH}$ solutions at $25^{\circ} \mathrm{C}$.

\section{Conclusion}

In summary, three-dimensional cubic ordered mesoporous carbons (CMK-8) were synthesized and palladium catalysts prepared with CMK-8 as supports by an impregnation-reduction method. The mass specific activities for formic acid oxidation of $\mathrm{Pd} / \mathrm{CMK}-8-\mathrm{I}$ and $\mathrm{Pd} / \mathrm{CMK}-8$-II were higher than that of $\mathrm{Pd} / \mathrm{C}$ as revealed from cyclic voltammetric investigations. It was also shown that the three-dimensional cubic ordered mesoporous carbon influenced significantly the electro-catalytic activity of Pd/CMK-8-I and Pd/CMK-8-II. Pd/CMK-8-II displayed the highest formic acid oxidation activity as a result of the very high surface area and the larger pore diameter which make diffusion of reactant and product easier. However, the effect of the pore diameter of the threedimensional cubic ordered mesoporous carbon (CMK-8) on the electro-oxidation formic acid is yet to be fully investigated. Chronoamperometric measurements revealed $\mathrm{Pd} / \mathrm{CMK}-8$ as being more stable than the commercial Pd/C catalysts. These improvements in electrochemical activity and stability make $\mathrm{Pd} / \mathrm{CMK}-8$ more advantageous for applications in direct formic acid fuel cells.

\section{Acknowledgments}

EPSRC and DSTL are acknowledged for support of this work. Taiwo thanks Keith Scott and Eileen Yu for the opportunity to work with their research group and the University of Lagos, Nigeria for financial assistance. A.B.A.N thanks the DAAD for a PhD scholarship.

\section{References}

[1] L. Feng, L. Yan, Z. Cui, C. Liu, W. Xing, J. Power Sources 196 (2011) 2469.

[2] A.S. Gago, D. Morales-Acosta, L.G. Arriaga, N. Alonso-Vante, J. Power Sources 196 (2011) 1324.

[3] W. Zhou, C. Wang, J. Xu, Y. Du, P. Yang, J. Power Sources 196 (2011) 1118.

[4] Y.C. Bai, W.D. Zhang, C.H. Chen, J.Q. Zhang, J. Alloy Compd. 509 (2011) 1029.

[5] J. Masud, M.T. Alam, M.R. Miah, T. Okajima, T. Ohsaka, Electrochem. Commun. 13 (2011) 86.

[6] S.A. Mamuru, K.I. Ozoemena, T. Fukuda, N. Kobayashi, J. Mater. Chem. 20 (2010) 10705.

[7] J. Ge, X. Chen, C. Liu, T. Lu, J. Liao, L. Liang, W. Xing, Electrochim. Acta 55 (2010) 9132.

[8] T. Maiyalagan, P. Siva kumar, Mater. Sci. Forum 657 (2010) 143.

[9] X. Xia, T.J. Iwasita, J. Electrochem. Soc. 140 (1993) 2559.

[10] T. Maiyalagan, F.N. Khan, Catal. Commun. 10 (2009) 433.

[11] C. Rice, S. Ha, R.I. Masel, A. Wieckowski, J. Power Sources 115 (2003) 229.

[12] X. Yu, P.G. Pickup, J. Power Sources 182 (2008) 124.

[13] G.Q. Lu, A. Crown, A.J. Wieckowski, J. Phys. Chem. B 103 (1999) 9700.

[14] T. Maiyalagan, J. Solid State Electrochem. 13 (2009) 1561.

[15] T. Maiyalagan, K. Scott, J. Power Sources 195 (2010) 5246.

[16] T. Maiyalagan, Int. J. Hydrogen Energy 34 (2009) 2874.

[17] W. Zhang, P.C. Sherrell, A.I. Minett, J. Razal, J. Chen, Energy Environ. Sci. 3 (2010) 1286.

[18] K. Lee, J. Zhang, H. Wang, D. Wilkinson, J. Appl. Electrochem. 36 (2006) 507.

[19] Y. Shao, J. Liu, Y. Wang, Y. Lin, J. Mater. Chem. 19 (2009) 46.

[20] T. Maiyalagan, Appl. Catal. B Environ. 89 (2008) 286.

[21] T. Maiyalagan, B. Viswanathan, U.V. Varadaraju, Electrochem. Commun. 7 (2005) 905.

[22] Y. Shao, J. Sui, G. Yin, Y. Gao, Appl. Catal. B 79 (2008) 89.

[23] X. Ji, K.T. Lee, R. Holden, L. Zhang, J. Zhang, Gianluigi A. Botton, M. Couillard, L.F. Nazar, Nat. Mat. 2 (2010) 286.

[24] L. Kong, H. Li, J. Zhang, Y. Luo, L. Kang, Appl. Surf. Sci. 256 (2010) 6688.

[25] J.R.C. Salgado, F. Alcaide, G. Álvarez, L. Calvillo, M.J. Lázaro, E. Pastor, J. Power Sources 195 (2010) 4022.

[26] E. Antolini, Appl. Catal. B 88 (2009) 1.

[27] S.H. Joo, S.J. Choi, I. Oh, J. Kwak, Z. Liu, O. Terasaki, R. Ryoo, Nature 412 (2001) 169.

[28] Z. Sun, X. Zhang, Y. Liang, H. Tong, R.L. Xue, S.D. Yang, H. Li, J.Electroanal.Chem. 633 (2009) 1.

[29] T. Kim, F. Kleitz, B. Paul, R. Ryoo, J. Am. Chem. Soc. 127 (2005) 7601.

[30] S. Jun, S.H. Joo, R. Ryoo, M. Kruk, M. Jaroniec, Z. Liu, T. Ohsuna, O. Terasaki, J. Am. Chem. Soc. 122 (2000) 10712.

[31] Y. Wan, Y. Shi, D. Zhao, Chem. Mater. 20 (2008) 932.

[32] T. Maiyalagan, T.O. Alaje, K. Scott, J. Phys. Chem.C 116 (2012) 2630.

[33] V. Radmilovic, H.A. Gasteiger, P.N. Ross, J. Catal. 15 (1995) 98.

[34] E. Antolini, F. Cardellini, J. Alloys Compd. 315 (2001) 118.

[35] M. Chen, Z.B. Wang, K. Zhou, Y.Y. Chu, Fuel Cells 10 (2010) 1171.

[36] Y. Suo, I. Hsing, Electrochim. Acta 55 (2009) 210.

[37] Y. Lee, J. Oh, H. Kim, J. Lee, S. Han, W. Choi, K. Park, J. Power Sources 195 (2010) 5896

[38] D. Acosta, J. Garcia, L.A. Godinez, H.G. Rodríguez, L. Contreras, L.G. Arriaga, J. Power Sources 195 (2010) 461.

[39] H. Duncan, A. Lasia, Electrochim. Acta 52 (2007) 6195.

[40] T.R. Soreta, J. Strutwolf, O. Henry, C.K. OSullivan, Langmuir 26 (2010) 12293.

[41] I. Park, K. Lea, S. Yoo, Y. Cho, Y. Sung, Electrochim. Acta 55 (2010) 4339.

[42] Z. Liu, L. Hong, M.P. Tham, T.H. Lima, H. Jiang, J. Power Sources 161 (2006) 831.

[43] Y. Lu, W. Chen, J. Phys. Chem. C 114 (2010) 21190.

[44] J. Yang, C. Tian, L. Wang, H. Fu, J. Mater. Chem. 21 (2011) 3384

[45] O. Winjobi, Z. Zhang, C. Liang, W. Li, Electrochim. Acta 55 (2010) 4217. 